\title{
The Ecology of Stress: linking life-history traits with physiological control mechanisms in free-living guanacos
}

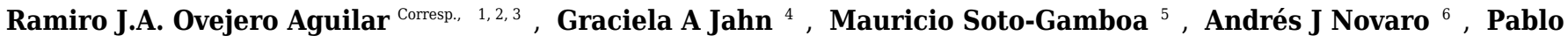 \\ Carmanchahi $^{3}$ \\ 1 Laboratorio de Interacciones Ecológicas, Universidad de Santiago de Compostela ((LIE) IADIZA-CCT-MENDOZA ), Mendoza, Argentina \\ 2 Instituto Argentino de Nivología, Glaciología y Ciencias Ambientales, Universidad Nacional de Cuyo, Mendoza, Argentina \\ 3 Grupo de Investigación de Eco-fisiología de Fauna Silvestre (GIEFAS), Asentamiento Universitario de San Martín de los Andes (AUSMA), Universidad \\ Nacional del Comahue (INIBIOMA-CONICET -AUSMA-UNCo), Neuquén, Argentina \\ 4 Laboratorio de Reproducción y Lactancia, Universidad de Mendoza (IMBECU- CCT-MENDOZA), Mendoza, Argentina \\ 5 Laboratorio de Ecología Conductual,Instituto de Ciencias Ambientales y Evolutivas, Facultad de Ciencias, Universidad Austral de Chile, Valdivia, Chile \\ 6 Programa Estepa-Andino Patagonica-CONICET-PATAGONIA NORTE-INIBIOMA, Neuquén, Argentina \\ Corresponding Author: Ramiro J.A. Ovejero Aguilar \\ Email address: rovejero@mendoza-conicet.gob.ar
}

Background-Providing the context for the evolution of life-history traits, habitat features constrain successful ecological and physiological strategies. In vertebrates, a key response to life's challenges is the activation of the Stress (HPA) and Gonadal (HPG) axes. Much of the interest in stress ecology is motivated by the desire to understand the physiological mechanisms in which the environment affects fitness. As reported in the literature, several intrinsic and extrinsic factors affect variability in hormone levels. In both social and non-social animals, the frequency and type of interaction with conspecifics, as well as the status in social species, can affect HPA axis activity, resulting in changes in the reproductive success of animals. We predicted that a social environment can affect both guanaco axes by increasing the secretion of testosterone (T) and Glucocorticoid (GCs) in response to individual social interactions and the energetic demands of breeding. Assuming that prolonged elevated levels of GCs over time can be harmful to individuals, it is predicted that the HPA axis suppresses the HPG axis and causes T levels to decrease, as GCs increase.

Methods-All of the data for individuals were collected by non-invasive methods (fecal samples) to address hormonal activities. This is a novel approach in physiological ecology because feces are easily obtained through non-invasive sampling in animal populations.

Results- As expected, there was a marked adrenal ( $p$-value $=.344 \mathrm{e}-12$ ) and gonadal ( $p$-value= 0.002656 ) response due to seasonal variation in Lama guanicoe. No significant differences were found in fecal GCs metabolites between males/females*season for the entire study period ( $p$-value $=0.2839$ ). Despite the seasonal activity variation in the hormonal profiles, our results show a positive correlation ( $p$ value $=1.952 \mathrm{e}-11, \mathrm{COR}=0.50)$ between the adrenal and gonadal system. The marked endocrine $\left(r^{2}=\right.$ $0.806)$ and gonad $\left(r^{2}=0.7231\right)$ response due to seasonal variation in male guanaco individuals highlights the individual's energetic demands according to life-history strategies. This is a remarkable result because no inhibition was found between the axes as theory suggests. Finally, the dataset was used to build a reactive scope model for guanacos.

Discussion-Guanacos cope with the trade-off between sociability and reproductive benefits and costs, by regulating their GCs and T levels on a seasonal basis, suggesting an adaptive role of both axes to different habitat pressures. The results presented here highlight the functional role of stress and gonad 
axes on a critical phase of a male mammal's life-the mating period-when all of the resources are at the disposal of the male and must be used to maximize the chances for reproductive success. 
1 The Ecology of Stress: linking life-history traits with physiological control mechanisms in free-living 2 guanacos

3

Ovejero Ramiro $^{\text {abe* }}$, Jahn Graciela $\mathrm{A}^{\mathrm{d}}$, Soto Gamboa Mauricio ${ }^{\mathrm{e}}$, Novaro Andrés J. ${ }^{\mathrm{f}}$, and Carmanchahi Pablo ${ }^{\mathrm{b}}$.

${ }^{a}$ Laboratorio de Interacciones Ecológicas (LIE) IADIZA-CCT-MENDOZA,Mendoza-Argentina.

${ }^{\text {b} G r u p o ~ d e ~ I n v e s t i g a c i o ́ n ~ d e ~ E c o-f i s i o l o g i ́ a ~ d e ~ F a u n a ~ S i l v e s t r e ~(G I E F A S), ~ A s e n t a m i e n t o ~ U n i v e r s i t a r i o ~ d e ~ S a n ~ M a r t i ́ n ~}$ de los Andes (AUSMA), Universidad Nacional del

Comahue (CONICET-INIBIOMA-AUSMA-UNCo), Neuquén, Argentina.

'Unidad de Dendrocronología, IANIGLA, CCT-Mendoza, Argentina

${ }^{\mathrm{d}}$ Laboratorio de Reproducción y Lactancia, IMBECU- CCT-MENDOZA, Mendoza, Argentina.

'Laboratorio de Ecología Conductual,Instituto de Ciencias Ambientales y Evolutivas, Facultad de Ciencias, Universidad Austral de Chile.

f Programa Estepa Patagónica y Andina, Centro de Ecología Aplicada del Neuquén, INIBIOMA-Universidad

Nacional del Comahue-CONICET, Junín de los Andes, Neuquén, Argentina

*Corresponding author: Ramiro Ovejero: e-mail:rovejero@mendoza-conicet.gov.ar

Author Contributions: OR originally formulated the idea, OR, SGM,NA and CP developed methodology, OR and CP conducted fieldwork, OR and JG generated the homonal data and laboratory analyses, OR performed statistical analyses, OR wrote the manuscript and JG,SGM,NA and CP provided editorial advice. 
Background-Providing the context for the evolution of life-history traits, habitat features constrain successful ecological and physiological strategies. In vertebrates, a key response to life's challenges is the activation of the

54 Stress (HPA) and Gonadal (HPG) axes. Much of the interest in stress ecology is motivated by the desire to 55 understand the physiological mechanisms in which the environment affects fitness. As reported in the literature, 56 several intrinsic and extrinsic factors affect variability in hormone levels. In both social and non-social animals, the 57 frequency and type of interaction with conspecifics, as well as the status in social species, can affect HPA axis 58 activity, resulting in changes in the reproductive success of animals. We predicted that a social environment can 59 affect both guanaco axes by increasing the secretion of testosterone (T) and Glucocorticoid (GCs) in response to individual social interactions and the energetic demands of breeding. Assuming that prolonged elevated levels of

61 GCs over time can be harmful to individuals, it is predicted that the HPA axis suppresses the HPG axis and causes T 62 levels to decrease, as GCs increase.

63

64 Methods-All of the data for individuals were collected by non-invasive methods (fecal samples) to address 65 hormonal activities. This is a novel approach in physiological ecology because feces are easily obtained through non-invasive sampling in animal populations.

67

68 Results- As expected, there was a marked adrenal ( $\mathrm{p}$-value $=.344 \mathrm{e}-12)$ and gonadal ( $\mathrm{p}$-value $=0.002656)$ response 69 due to seasonal variation in Lama guanicoe. No significant differences were found in fecal GCs metabolites between 70 males/females*season for the entire study period ( $p$-value $=0.2839)$. Despite the seasonal activity variation in the 71 hormonal profiles, our results show a positive correlation ( $\mathrm{p}$-value $=1.952 \mathrm{e}-11, \mathrm{COR}=0.50)$ between the adrenal and 72 gonadal system. The marked endocrine $(\mathrm{r} 2=0.806)$ and gonad $(\mathrm{r} 2=0.7231)$ response due to seasonal variation in 73 male guanaco individuals highlights the individual's energetic demands according to life-history strategies. This is a 74 remarkable result because no inhibition was found between the axes as theory suggests. Finally, the dataset was used 75 to build a reactive scope model for guanacos.

76 Discussion-Guanacos cope with the trade-off between sociability and reproductive benefits and costs, by regulating 77 their GCs and T levels on a seasonal basis, suggesting an adaptive role of both axes to different habitat pressures. 
78 The results presented here highlight the functional role of stress and gonad axes on a critical phase of a male

79 mammal's life - the mating period - when all of the resources are at the disposal of the male and must be used to

80 maximize the chances for reproductive success.

81

82

83

84

85

86

87

88

89

90

91

92

93

94

95

96

97

98

99

100

101

102

103

104

105

106

107

108

109

110

111

112

113

Key-words: Stress ecology, hormonal profiles in wildlife, Lama guanicoe, sociality, reproduction, non-invasive methods.

\section{Introduction}

Natural selection shapes phenotypic traits that permit organisms to respond appropriately to intrinsic and extrinsic factors (Darwin, 1959; Roff, 1992; Stearns, 1992; Bozinovic, 2002; Nespolo et al., 2003). Phylogeny and genetic variation among organisms determine the resource allocation trade-offs among life-history traits (e.g. agespecific growth, reproduction and survival schedules, and sociability). Environmental, ecological, and demographic processes (extrinsic factors) create selective pressures that impinge on an organism's lifetime fitness (Stearns, 1992; Zera \& Harshman, 2001). Therefore, understanding life-history variation among taxa from an evolutionary perspective requires an understanding of the physiological mechanisms that link genes with phenotype and how extrinsic factors regulate trade-offs between survival and reproduction. Furthering our knowledge of ecophysiological mechanisms, and particularly endocrine mechanisms, is key to understanding how life-history variation and trade-offs arise and are retained (Ketterson \& Nolan 1999; Zera \& Harshman, 2001; Crespi et al., 2013).

The stress response is a mechanism by which an individual of a given species copes with environmental changes (stressors) (Boosntra et al., 2001; Winfield, 2005; Romero et al., 2009; Ovejero and Carmanchahi, 2012; Ovejero 2013). Perception of a stressful situation activates the sympathetic adrenomedullary system and the 
114 hypothalamic pituitary adrenocortical (HPA) axis (Mostl and Palme, 2002). Activation of the HPA axis stimulates 115 the release of steroid hormones (glucocorticoids GCs, e.g., corticosterone, cortisol). GCs in turn activate the 116 mobilization of energy necessary to cope with adverse environmental conditions (Dallman et al., 2007; Sapolsky, 117 2000).

In the last 30 years, the term stress has been strongly criticized due to its ambiguity and several authors 119 have researched the allostasis theory and attempted to connect biomedical and ecological data (McEwen \& 120 Wingfield 2003; Romero et al., 2009, 2011). Allostasis is the daily and seasonal process that allows organisms to 121 maintain physiological parameters (homeostasis) within life-sustaining ranges, which occur via allostatic mediators 122 (McEwen \& Wingfield, 2003). The allostatic model generated criticism and Romero et al. (2009) proposed the 123 reactive scope model, attempting to retain the strengths but avoid the weaknesses of the allostatic model. The present work contributes to the debate about the applicability of the allostatic model to nature. allostasis) can negatively affect behavior, reproduction, immune function and growth through prolonged activation of the HPA axis (Moberg, 1991; Boonstra and Singleton, 1993; Goymann and Wilngfield, 2004; Pride, 2005;

128 Pereira et al., 2006). Glucocorticoids (GCs) are often considered the allostatic mediators of the stress response, and 129 they have been the focus of research for decades (Sapolsky, 2000; Ovejero 2013). Much less is known, however, 130 about the role of GCs' in free-living animals (Bonier et al., 2009). The role of baseline or stress-induced GC in the 131 modulation of an individual or populations performance, is still essentially unknown. Understanding, social factors 132 and their endocrine correlates (baseline measures of GCs and T) in wild animals has potential implications for 133 wildlife management, population ecology, reproductive biology and evolution. The social environment is therefore 134 one of the primary sources of information that can induce allostatic responses (Boonstra et al., 2001; Rubenstein and 135 Shen, 2009; Creel et al., 2013). It's expected that in both social and non-social animals, the frequency and type of 136 interaction with conspecifics, as well as status in social species,can affect HPA and HPG axis activity and ultimately 137 the reproductive success of animals. 
141 This physiological mechanism (androgen response) modulated by social environment, is likely to be mainly

142 important when considering their roles (testosterone-mediated traits) in the evolution of mating systems and life

143 histories (Wingfield et al., 1997; Knapp and Moore, 1997; Faulkes and Abbott, 1997; Hirschenhauser and Oliveira,

144 2006; Young et al., 2006; Rubenstein et al., 2009; McGlothilin et al., 2010). In addition, testosterone levels can also

145 affect female preference (Enstrom et al., 1997), thus influencing fitness through both intra and intersexual selection;

146 (Sinervo et al., 2000). Although the role of short-term androgen changes has not been completely described, these

147 have long been associated with territoriality (McGlothilin et al., 2010). The "Challenge Hypothesis" (first described

148 in bird studies) predicts that androgen levels and agonistic interactions are positively related and are socially-context

149 dependent (Wingfield et al. 1997). Among mammals, these predictions have recently been tested, and a positive

150 correlation was found between social cues and testosterone levels associated with territorial defense, group

151 formation, social dominance and hierarchy formation during the breeding season (Muller and Wrangham 2004;

152 Creel et al. 2013). Consequently, social stressors provide a context where the individual must respond to a series of

153 repeated stressors over time, depending on the frequency and intensity of the stimulus, and this can lead to various

154 physiological problems, (see, Sapolsky 2002).

155

156

157

158

159

160

161

162

163

164

165

166

167

168
Much of the variation in life histories strategies reflects individuals' phenotypic responses to environmental challenges and perceived risks. The adrenal and gonadal system strongly influence behavior, control the annual cycle of development, modulate behavioral and physiological responses to the environment, and establishes important incompatibilities in life stages. It provides a model for studying the connections between mammal physiology and life history. Guanacos (Lama guanicoe) are the largest social artiodactyls of South America, and these organisms have a polygynous resource-defense mating system. This wild and endemic camelid has been successfully used as a study model of behavioral interactions (De Lamo et al., 1998; Franklin, 1982; Marino and Baldi, 2008, Taraborelli et al. 2014) ecological studies (Puig and Videla, 1995; Bank et al., 2003; Puig et al., 2008; Acebes et al., 2010; Ovejero et al. 2011; Ovejero, 2013; Marino and Baldi, 2014; Radovani, 2004) and management (Montes et al., 2006; Zapata et al., 2002; Bonacic et al., 2003,Zapata et al., 2004), but information about the guanaco's physiological ecology remains scarce. More recently, guanacos have also been used as a model of stress response; a study was conducted to determine how management including handling, shearing, and release induce changes in circulating steroid hormones Carmanchahi et al., (2011), however this work was based on an invasive sampling method.

PeerJ reviewing PDF | (2016:06:11122:1:1:REVIEW 26 Sep 2016) 
To understand how physiology mediates the relationship between life history and the environment, we

170

171 GCs due to individual social interactions and the energetic demands of the breeding season. (B)-Male guanacos will 172 show seasonal variation in the activity of their adrenal and gonadal systems, which perform incompatible functions 173 in different life stages (survival vs reproduction). (C)-Prolonged elevated baseline levels of GCs in male guanacos 174 due to long periods of intense social interaction will be detrimental, costly, and decrease fitness, and we would 175 expect that in this case HPA inhibits the activity of the HPG. Together, these predictions provide a description of the 176 177 178 179

180

181

182

183

184

185

186

187

188

189

190

191

192

193

194

195

196

197

198

199

200

201 reactive scope model and an understanding of how physiological mechanisms might constrain patterns of variation in wild South-American camelid life histories. These predictions might also provide the basis for future mammalian studies targeted at understanding phenotype-environment interactions.

\section{Methods}

\section{Ethics Statement}

The present study did not warrant capturing or handling protected or endangered animals. All of the data for individuals were collected by non-invasive methods (fecal samples) to address hormonal activities. This is a novel approach in physiological ecology because feces are easily obtained through non-invasive sampling in animal populations. This is important because the handling necessary for collection of plasma can confound estimates of baseline GC measurements. The described field studies were carried out in a protected area with a permit (files:NO 4350-000019112/Res 238) from the DRNR (Dirección de Recursos Naturales Renovables, Mendoza).

\section{Non-invasive methods to address hormonal activities}

Fresh fecal samples were collected from 334 wild adult male guanacos from La Payunia reserve (36.000S and 36.360S; 68.340W and 69.230W, South of Mendoza Province, Argentina). The samples were collected during 7 field surveys (15 days each month) over the course of a year. Fresh feces samples were collected from focal individuals (one sample per each indiv.) and were labeled according to the sample location, time, sex, age and social structure (family group, bachelors group and solitary male). To slow microbial activity and to reduce immunoreactivity problems, the samples were frozen immediately in liquid nitrogen and stored at $-20 \mathrm{C}^{\mathrm{o}}$ until the 
202 time of analysis (Laboratorio de reproducción y lactancia-LARLAC-IMBECU-CONICET-MENDOZA). Fieldwork

203 was conducted during the breeding and non-breeding months to assess seasonal variation in hormone levels. We

204 choose this period (from September to March) because during the beginning of the breeding season, guanaco males

205 are exposed to intense social instability caused by agonistic interactions with other males due to territory 206 establishment and hierarchies (Ovejero 2013) and at the end males are exposed to female defense interactions. This

207 suggests that for guanaco males, female or territory defense strategies demand higher energetic costs. This is 208 expected if one assumes that defending a female or territory are the principal objective (and target) of a male that 209 wants to maximize the probabilities of leaving an offspring. We expected that this behavioural expression have 210 physiological mechanism that could explain this difference. During the non-breeding season (from April to August), 211 a period with less intense social interactions, we expected lower activity on hormonal mechanism.

212 Furthermore, $100 \%$ of the sampling surveys were done in the same sites. Steroids were extracted from lyophylized

213 fecal samples according to a protocol developed for fecal steroid metabolite extraction for free-range ungulates (for 214 more detail see, Ovejero 2013). The commercial ${ }^{125}$ I-cortisol and ${ }^{125}$ I-testosterone RIA-KITS (BECKMAN, Coulter 215 Company IM-1841/IM-1119-Immunotech-, Prague, Czech Republic) were used to quantify the levels of cortisol and 216 testosterone in the samples (for more detail see, Ovejero 2013). The analytical sensitivity of the cortisol assay is $2173.075 \mathrm{ng} / \mathrm{mL}$. The antibody used in the immunoassay is highly specific for cortisol (100\% cross-reaction). The 218 cross-reactivity to other naturally occurring steroids is very low, for example: aldosterone $<0.1 \%$; $8.4 \%$ 219 corticosterone; cortisone $1.5 \% ; 11$-desoxy-cortisol $18 \%$, etc. The analytical sensitivity of the testosterone assay is $220 \quad 0.025 \mathrm{ng} / \mathrm{mL}$. The antibody used in the immunoassay is highly specific for testosterone (100\% cross-reaction). The 221 cross-reactivity to other naturally occurring steroids is very low, for example: $0.00014 \%$ aldosterone; estrone $222<0.3 \% ; 0.08$ androsterone; 5-Dihydrostestosterone $10 \% \alpha ; 11 \beta$-Hydroxytestosterone $2 \%$; corticosterone $8.4 \% ; 1.5 \%$ 223 cortisone; cortisol 11-deoxy-18\%, etc. In addition, all samples were assayed in triplicate (extraction efficiency test) 224 and duplicate (binding and parallelism test) and reanalyzed whenever the resulting coefficient of variation exceeded $22520 \%$. Intra- and inter-assay coefficients of variation of GCs-immunoassay were $6.5 \%$ and $11.2 \%$ and for testosterone 226 immunoassays were 9.5 and $13.4 \%$, respectively.

\section{Statistical analyses}


Welch two sample T-tests were used to evaluate the seasonal variation response of steroid hormones.

232 Furthermore, two-way ANOVAs were used to evaluate the interaction between sex and season. Generalized linear 233 models were developed (n polynomials function $=f(x)=a_{n} X^{n}+a_{n 1-1} X^{n}-1+a_{n-2} X^{n}-2+\ldots$ ) to describe the

234 hormonal profiles and their seasonal variation in response to the environment. Moreover, a Pearson's correlation 235 was used to test the activity association between the adrenal and gonadal system throughout the year. All statistical 236 analyses were conducted using R statistical software version 3.1.0 (Development Core Team, 2012).

237

238

239

240

241

242

243

244

245

246

247

248

249

250

251

252

253

254

255

256

257

258

259

260

\section{Results}

\section{Ecological process and fecal-hormone profiles in wild guanacos}

As expected, there was a marked adrenal $(\mathrm{t}=7.4016, \mathrm{df}=302.174, \mathrm{p}$-value $=1.344 \mathrm{e}-12,1-\alpha(0.90)=$ 7.661734-12.057391, mean $=25.75864 / 15.89907$ breeding and non-breeding season respectively) and gonadal $(\mathrm{t}=3.2873, \mathrm{df}=28.948, \mathrm{p}$-value $=0.002656,1-\alpha(0.90)=0.6213-1.9508$, mean $=3.209810 / 1.923700$ breeding and non-breeding season respectively for male groups) GCs and T response due to seasonal variation in Lama guanicoe individuals. This highlights the individual's energetic demands according to life-history strategies. No significant differences were found in the amounts of fecal GC metabolites between males/females*season for the entire study period $(\mathrm{F}=1.0757, \quad d f=143.529, \quad p$-value $=0.2839 ; \quad$ male: $\quad \mathrm{ng} / \mathrm{gr}=22,42,1-\alpha(0.90)=1.6887$, std-e $=0.86$, $\mathrm{n}=251$;female:ng/gr=20,71,1- $\alpha(0.90)=2.6079, \mathrm{n}=76$, std-e $=1.33)$. This result was not expected as it was thought that there would be a difference in the allocation of resources to cope with the different roles that that males and females have in a population. Despite the seasonal activity variation in the hormonal profiles, our results show a positive correlation $(\mathrm{t}=7.1524, \mathrm{df}=184, \mathrm{p}$-value $=1.952 \mathrm{e}-11, \mathrm{CI}=0.34574000 .5719168, \mathrm{COR}=0.50)$ between the adrenal and gonadal system; both peaks of activity concur with the reproductive season. Our last prediction state that, prolonged elevated baseline levels of GCs due to long periods of intense social interaction are detrimental, costly and decrease fitness; it is expected that in this context, HPA inhibits the activity of the HPG. The marked endocrine $\left(y=0.0743 \times 5-1.9677 \times 4+19.136 \times 3-82.442 \times 2+147.4 x-58.902 ; r^{2}=0.806\right)$ and $\operatorname{gonad}(y=0.0041 \times 5-0.1102 \times 4$ $\left.+1.0889 \times 3-4.6819 \times 2+7.914 x-0.7892 ; r^{2}=0.7231\right)$ response due to seasonal variation in male guanaco individuals (Figure 1) highlights the individual's energetic demands according to life-history strategies. This is a remarkable result because no inhibition was found between the axes as theory suggests. Finally, the dataset was used 
261 to build a reactive scope model for guanacos, see Figure 2. Most studies measure only one physiological mediator at

262 a time; here the concentration of two mediators is placed on the y-axis for a given time point. This was done because

263 these mediators are correlated in the functional role that each one plays in the normal reactive scope range. In other

264 words, both mediators encompass responses to cope with predictable and unpredictable changes in the environment.

265 Our result shows the ranges of predictive/reactive homeostasis and homeostatic overload/failure. These ranges

266 consist of the seasonal set of point ranges for the physiological mediators. The mediators are correlated in terms of

267 the functional role that each one plays in the normal reactive scope range. In other words, both mediators encompass

268 responses for coping with predictable and unpredictable changes in the environment. The values of each mediator

269 are presumed to exist in four general ranges. The minimum (5-10 Ng.gr for C;1-2 Ng.gr for T) and maximum (20-35

270 Ng.gr for C;3-4 Ng.gr for T) concentration of the mediator was presumed to constitute a threshold. The results show

271 the ranges of predictive/reactive homeostasis $(\mathrm{PH} / \mathrm{RH})$ and homeostatic overload/failure, the stress-gonadal and

272 feedback response indicates the max-min activity patterns for HPA \& HPG axis during one year. These results 273 consist of the seasonal set of point ranges for the physiological mediators.

\section{Discussion}

Our results confirm the prediction that "Social environment positively affects the HPG and HPA axes by raising the secretion of $\mathrm{T}$ and GCs due to individual social interactions and the energetic demands of the breeding season." Further to this, our results suggest that social environment and breeding season are stressful scenarios for male guanacos. These scenarios are seen to produce associated costs such as increased metabolic rate and energy expenditure due to: territorial/female defense (male-reproduction strategies), male social dominance hierarchies, reproduction, and increased exposure to predators during the breeding season. If the data value observed in March is

283 taken as a baseline cortisol level, cortisol is seen to increase by one and a half times during the non-breeding season 284 and three times during the breeding season. If the March testosterone measurement is taken as the basal testosterone 285 level, the same pattern is seen; the hormonal profile increases during the non-breeding and breeding seasons. This 286 highlights the importance of the functional roles of the HPA and HPG axes during the reproductive period, as well 287 as the adaptive roles they play in the seasonal pattern observed, allowing the species to meet environmental 288 challenges as well as challenges throughout its life cycle. 
From the results gathered in this study, different inmunoreactive GCs and $\mathrm{T}$ secretion patterns were

290

291

292

293

294

295

296

297

298

299

300

301

302

303

304

305

306

307

308

309

310

311

312

313

314

315

316

observed according to the mating system and reproduction strategies (territorial defense and female defense) that guanaco males (of a migratory population) adopt during the breeding season (Ovejero 2013). Our results highlight the functional role of the stress and gonad axes during the critical mating period when all of the resources at a male's disposal must be used to maximize the chances of reproductive success. Generally, it appears that $\mathrm{T}$ is immediately involved in aggression associated with reproduction, rather than with other forms of aggression (e.g., anti-predator aggression, Moyer 1968; Wingfield and Marler 1988). The data here presented support the correlation between T patterns and reproductive strategies (establishment and maintenance of a breeding territory and mate-guarding) proposed by Wingfield et al.,(1990) for male birds. However, this study extends Wingfield' et al., (1990) finding to mammals. In 1984, the same authors proposed that males of polygynous species may have higher levels of $\mathrm{T}$ for longer periods during the breeding season than do males of monogamous species. Our results highlight the functional role that $\mathrm{T}$ levels have in determining and maintaining the polygynous mating system in guanacos, but we predict that this pattern could be altered in guanaco populations that coexist with human activities that fragment the guanaco's normal distributional range. For example, the use of fences by rural settlers has a direct impact on the space used by guanacos, and it is possible that this could promote some groups (within a population) to adopt monogamous behavior (Marino and Baldi 2008).

On the other hand, our results highlight the notorious decrease in the activity pattern of the stress and gonadal axes during the non-breeding season. This result was not expected because individuals must cope with another critical phase of autumnal migration at this time, therefore we expected that all of the resources (in terms of energy) would be available to maximize the chances for survival success during the migration trip. These results confirm our prediction that "guanacos show a seasonal variation in the activity of their endocrine and gonadal systems and incompatible functions (reproduction an self-maintenance) are established during different life stages." In winter, food intake by birds and mammals needs to be geared towards preventing starvation while at the same time maintaining an optimum body mass to permit rapid escape from predators. GC concentrations may be the critical factor determining the size of the fat reserves and either environmental severity or predation risk (Winglfied 1990). The GC hormone, corticosterone, is thought to be important in the physiological orchestration of avian migration because of the identified elevated level of activity of the avian adrenal gland either prior to or during migration (Naik and George 1963; John 1965; Peczely 1976). Preparation for migration and for winter requires a 
317 period of hyperphagia and a laying down of fat reserves (for a review, see Holberton et al. (1999). In birds, 318 Wingfield and Silverin (1986); Astheimer et al. (1992) and mammals, Dallman et al. (1993), GCs play a vital role in

319 foraging behavior and hyperphagia, with low to moderate concentrations stimulating feeding behavior. As is noted 320 by O'Reilly and Wingfield (1995) migrating birds show increased baseline concentrations of GCs but a reduced 321 stress response. An adaptive explanation for this pattern is the migration modulation hypothesis, Holberton et al.

322 (1996, 1999). It proposes that higher than average concentrations of baseline GCs are expressed prior to and during 323 migration to facilitate migratory fattening. However, the stress response is lowered when challenged so that the 324 negative, catabolic effects of high GCs on skeletal muscle do not occur; thus, critical skeletal muscles are preserved 325 for flight during migration. As such, this hypothesis may explain the non-breeding season hormonal profiles 326 generated in this study, but more data is needed to test these assumptions. Another explanation may suggest that 327 migration (in terrestrial system) could be regulated by other endocrine mechanisms (and other hormones) involved 328 in generating fat reserves and foraging behavior such as those that involve the thyroid gland Schwabl et al. (1984). 329 Mattocks (1976) shows that gonad hormones (at least in some species) have a functional role (fat deposition) before 330 spring migration. This may suggest that the increased activities of the gonad axis compared with the stress axis in 331 guanacos could have an important role in the "migration to and from the winter range", but to confirm this 332 prediction more experimental and field studies would be needed.

333 The last prediction of this study, that "prolonged elevated baseline levels of GCs due to long periods of 334 intense social interaction will be detrimental, costly and decrease fitness" was not validated by the results gathered.

335 Our interest in the relationships between social or environmental conditions and stress-gonadal hormone 336 concentrations (for both social and non-social species) is motivated by a desire to understand the physiological 337 mechanisms by which the environment affects fitness. However, understanding the relationship between hormonal 338 profiles and fitness is not straightforward, therefore this study attempts to obtain proxies that would help us begin to 339 resolve this relationship. We consider that taken together, the interplay between stress/gonad hormones across 340 seasonal variation could be an interesting proxy to "establish" causal relationships between hormonal levels and 341 ecological correlates. For example, some authors have stated that prolonged elevated baseline levels of GCs are 342 commonly viewed to be detrimental, costly and decrease fitness, Bonier et al. (2009). However, there is scarce 343 evidence for this negative association. Part of the problem with this approach is the variation among species in 344 terms of their hormones/fitness relationships, and this variation can be attributed to a variety of demographic, social 
345 (e.g. social rank, age, sex, group size) or environmental factors (e.g. resource availability). Additionally, for a 346 variety of vertebrate taxa, seasonal variation in GC levels has been reported to be due to varying food availability, 347 temperature, rainfall and tourist activity (Romero 2002; Tempel and Gutierrez 2004), however it still remains 348 unclear if this holds true for mammals. The other issue is that many of the studies of HPA-fitness relationships 349 reviewed by Bonier et al. (2009) were conducted during the breeding season alone. The study herein presented 350 provides a full set of data (hormone profiles) across seasonal variation throughout the course of an entire year. As 351 expected, guanacos cope with this trade-off between sociability and reproductive benefits and costs by regulating 352 their GCs and testosterone levels on a seasonal basis like other mammals (Boosntra 2005), and they may also 353 experience fine adjustments on a daily basis. We suggest that elevated levels of GCs in guanacos due to highly 354 social interactions during the breeding season may play a fundamental role in the regulation of enhanced metabolic 355 needs during reproduction. Guanaco males, like other iteroparous males, exhibit high concentrations of cortisol, a 356 gonadal axis that is not inhibited by high GC concentrations, so the last prediction presented in this work must be 357 rejected. Furthermore, during the breeding season, our results show two GC peaks of activity, one at the beginning 358 and another at the end of the breeding season. In the former, guanaco males are exposed to intense social instability 359 caused by agonistic interactions with other males due to territory establishment and hierarchies. In the latter, 360 guanaco males are exposed to female defense interactions. This suggests that for guanaco males, female defense 361 strategies demand higher energetic costs when compared to territory defense strategies. This is expected if one 362 assumes that defending a female (rather than a territory) is the principal objective (and target) of a male that wants to 363 maximize the probabilities of leaving an offspring. Moreover, birth rate data for the population was collected from 364 2007-2008 (hormonal measures)-2009, so if one expects a negative relationship between the hormonal profiles, one 365 would also expect to see a negative value for the proportion of offspring per adult. The birth rate values for those 366 years were $0.14,0.28$ and 0.29 respectively; thus with these results one can expect that there is no detrimental effect 367 on individual-population fitness.

368 The lesser HPA axis activity measured during the non-breeding season confirms the prediction "that 369 reproduction and sociability may be long-term and predictable." This is likely the case because this period is 370 associated with fewer social interactions. The individual hierarchies are more relaxed because the animals are 371 preparing to migrate (Novaro pers. com.) and the species strategy at this time is to survive and to not reproduce. 
373 show the ranges of predictive/reactive homeostasis and homeostatic overload/failure ranges; these consist of the

374 seasonal set of point ranges for the physiological mediators. For guanacos, the normal reactive scope is described 375 with two GCs and T set point ranges. The model was made to reflect the natural progression of life-history stages 376 such as breeding. Furthermore, the minimum concentration of the mediator was presumed to constitute a threshold.

377 Subsequently, a GC and T threshold was proposed, and below this limit it is seen that the individual/population 378 enters into homeostatic failure. This threshold is predicted to indicate the minimum concentration of GCs and T 379 mediator necessary to sustain guanacos seasonal life changes (in natural conditions). However, more studies are 380 needed to test this prediction. On the other hand, above the upper end of the normal reactive scope, when a 381 physiological mediator exceeds the reactive homeostatic range, the individual/population enters into homeostatic 382 overload (pathological states). This threshold is predicted to indicate the maximum concentration of GCs and T 383 mediator necessary to sustain seasonal life changes in guanacos (in natural conditions). However, more studies are 384 needed to test this prediction especially considering that pharmacological stimulation may allow individuals to reach 385 a higher threshold though this would not be considered within the scope of natural changes.

386

387

388

389

390

391

392

393

394

395

396

397

398

399

\section{Conclusions}

Knowledge of physiological and behavioral mechanisms is key to understanding how life-history variation and trade-offs might arise and help organisms cope with environmental variation. Mechanistically, trade-offs result from the need to differentially allocate limited resources to traits like reproduction versus self-maintenance, with selection favoring the evolution of optimal allocation mechanisms. Guanacos cope with the trade-off between sociability and reproductive benefits and costs by regulating their GCs and T levels on a seasonal basis. This seasonal regulation suggests the adaptive and functional role of both axes in regulating energy allocation for predictable life-history events (like reproduction). During breeding, and event with highly social interactions, elevated baseline levels of GCs and T may actually be predictive of high reproductive success. Our results support the assumption that GCs via the HPA axis did not suppress the HPG axis and did not diminish T levels during....(no habria que indicar el period estacional en que paso esto?_). From this, we propose that guanacos anticipate stressors with acute impacts and the duration is moderated by physiological consequences (i.e. reproduction). During the nonbreeding season, a period with less intense social interactions, lower baseline levels of GCs and T may actually be 
400

401

402

403

404

405

406

407

408

409

410

411

412

413

414

415

416

417

418

419

420

421

422

423

424

425

426

427

428

429

430

predictive of a high probability of survival. Our study provides a model for further study of the links between physiology and life history.

Studying both the HPA and the HPG axes was an informative approach to understand the functional mechanisms that animals use to cope with stress. Studying these two axes simultaneously is important because the key circulating steroid hormones of the stress axis, GCs, influence the expression of approximately $10 \%$ of the genome. Some of the targets of GCs include genes controlling metabolism, growth, repair, reproduction, and management of resource allocation (Lee et al. 2005). However, both axes play fundamental roles not just when animals are experiencing stress, but also during normal periods of survival and growth. Therefore, these axes mediate the adaptation of the organism to its environment. At the individual level, the stress axis plays a key role in allowing animals to respond to the changes and challenges of both environmental certainty and uncertainty. At the species level, the stress axis plays a central role in evolutionary adaptation to particular ecological pressures.

Acknowledgements: We appreciate the comments and suggestions made by Dr. Francisco Bozinovic, Donald R.Strong and Tim Coulson on earlier versions of this manuscript. We thank Nelly Horak and Emily Giles for help with the English language. The park rangers and other staff of La Payunia Provincial Park helped us throughout different stages of this work.

Figure 1. HPA \& HPG axis activity patterns throughout the study period. Blue line= the seasonal baseline fecal testosterone profile (defined by $\left.\mathrm{y}=0.0041 \mathrm{x} 5-0.1102 \times 4+1.0889 \times 3-4.6819 \times 2+7.914 \mathrm{x}-0.7892 ; \mathrm{r}^{2}=0.7231\right)$, Pink line $=$ the seasonal baseline fecal cortisol profile (defined by $\mathrm{y}=0.0743 \times 5-1.9677 \mathrm{x} 4+19.136 \times 3-82.442 \times 2+147.4 \mathrm{x}-58.902 ; \mathrm{r}^{2}$ $=0.806)$. There was marked adrenal and gonadal activity during the breeding and non-breeding $(\mathrm{CI}=7.661734-$ 12.057391 , mean $=25.75864 / 15.89907$ respectively) season respectively for the male groups, the GCs and $\mathrm{T}$ response was due to seasonal variation in the guanacos highlighting the individual's energetic demands according to life-history strategies.

Figure 2. Most studies measure only one physiological mediator at a time, here the concentration of two mediators (cortisol-C /testosterone.T) is placed on the $\mathrm{y}$-axis at a given time point. The mediators are correlated in terms of the functional role that each one plays in the normal reactive scope range. In other words, both mediators encompass responses for coping with predictable and unpredictable changes in the environment. The values of each mediator are presumed to exist in four general ranges. The minimun (5-10 Ng.gr for C;1-2 Ng.gr for T) and maximun (20-35 
431 Ng.gr for C;3-4 Ng.gr for T) concentration of the mediator was presumed to constitute a threshold. The results show

432 the ranges (double arrows) of predictive/reactive homeostasis (PH/RH) and homeostatic overload/failure, the stress-

433 gonadal and feedback response (gray circles) indicates the max-min activity patterns for HPA \& HPG axis during

434 one year. The $\mathrm{C}$ activity patterns in guanacos shows two peak of RH (dotted lines) in the reproductive season,

435 between Ag./O. males adopts a territory-defense strategies at the beginning of the reprod. season; during Ja./F.

436 males changes to a female-defense strategies at the ends of the reprod. season. These results consist of the seasonal

437 set of point ranges for the physiological mediators.

438

439

440

441

442

443

444

445

446

447

448

449

450

451

452 453

\section{References}

Bank MS, Sarno RJ, Franklin WL (2003) Spatial distribution of guanaco mating sites in southern Chile: conservation implications. Biological conservation. 112: 427-434.

Blanchard RJ, McKittrick CR, Blanchard DC (2001) Animal models of social stress: effects on behavior and brain neurochemical systems. Physiol. Behav. 73, 261-271.

Becker JB (2002) Behavioral endocrinology 2nd ed. Massachusetts Institute of technology. 1-749.

52 Bonacic, C and Macdonald, DW (2003). The physiological impact of wool-harvesting procedures in vicunas (Vicugna vicugna). Animal Welfare 
454 Bonier F, Moore IT, Martin PR \& Robertson RJ (2009) The relationship between fitness and baseline

455

456

457

458

459

460

461

462

463

464

465

466

467

468

469

470

471

472

473

474

475

476

477

478

479

480

481

482

483

484

485

486

487

488

489

490

491

492

493

494

495

496

497

498

499

500

501

502

503

504

505

506

507

glucocorticoids in a passerine bird. General and Comparative Endocrinology, 163, 208-213.

Boonstra R, Singleton GR (1993) Population declines in the snowshoe hare and the role of stress, Gen. Comp. Endocrinol. 91, 126-143.

Boonstra, R. (2005) Equipped for life: the adaptive role of the stress axis in male mammals. Journal of Mammalogy, $86,236-247$.

Boonstra R, Barker JM, Castillo J \& Fletcher QE (2007) The role of the stress axis in life-history adaptations of rodents. Rodent Societies: An Ecological and Evolutionary Perspective (eds J.O. Wolff \& P.W. Sherman), pp. 139149, University of Chicago Press, Chicago.

Boonstra R, McColl CJ, Karels TJ (2001) Reproduction at all costs: the adaptive stress response of male arctic ground squirrels. Ecology 82: 1930-1946.

Bozinovic F (2002) Physiological ecology and evolution. Theory and study cases in vertebrates. Ediciones Universidad Catolica de Chile. Pp.531.

Buchanan KL, Goldsmith AR (2004) Noninvasive endocrine data for behavioural studies: the importance of validation. Anim Behav 67:183-185.

Busch DS and Hayward LS (2009) Stress in a conservation context: a discussion of glucocorticoid actions and how levels change with conservation-relevant variables, Biol. Conserv. 142, 2844-2853.

Carmanchahi P, Ovejero RJA, Mar ull C, López C, Schroeder N, Jahn G, Novaro A y Somoza G (2011). Physiological response of wild guanacos to capture for live shearing. Wildlife research: csiro publishing. vol. $\mathrm{N}^{\circ}$. P61 - 68 .

Cavigelli SA (1999) Behavioural patterns associated with faecal cortisol levels in free-ranging female ringtailed lemurs, Lemur catta. Anim Behav 57:935-944.

Cavigelli S, Pareira M (2000). Mating season aggression and fecal testosterone levels in male ring-tailed lemurs (Lemur catta). Horm.

Behav. 37, 246-255.

Clarke FM, Faulkes CG (2001) Intracolony aggression in the eusocial naked mole-rat, Heterocephalus glaber. Anim. Behav. 61, 311-324.

Clarke FM, Bennett NC (2001) Family values: group dynamics and social control of reproduction in African molerats. Trends Ecol. Evol. 16, 184- 190.

Clutton-Brock TH, Brotherton PNM, Russell AF, O'Riain MJ, Gaynor D, Kansky R, Griffin A, Manser M, Sharpe L, McIlrath GM, Small T, Moss A, Monfort S (2001) Cooperation, control, and concession in meerkat groups. Science 291, 478-481.

Co^te' SD (2000) Dominance hierarchies in female mountain goats: stability, aggressiveness and determinants of rank. Behaviour 137, $1541-1566$.

Creel S, Creel N y Monfort S (1996). Social stress and dominance. Nature 379:212.

Creel S (2001) Social dominance and stress hormones. Trends Ecol. Evol.16, 491- 497.

PeerJ reviewing PDF | (2016:06:11122:1:1:REVIEW 26 Sep 2016) 
508 Creel S, Dantzer B, Goymann W \& Rubenstein DR (2013) The ecology of stress: effects of the social environment. 509 Functional Ecology, 27, 66-80.

510

511 Creel S \& Creel NM (2002) The African Wild Dog: Behavior, Ecology and Conservation, Princeton University 512 Press, Princeton, NJ.

513 Crespi, E J, TD Williams, T S Jessop, and B Delehanty (2013). Life history and the ecology of stress: how do 514 glucocorticoid hormones influence life-history variation in animals? Funct. Ecol. 27(1):93-106.

515 Darwin C, (1959). On the origin of species by means of natural selection, or the preservation of favoured races in the struggle for life. London: Murray. [1st ed.]

Dallman MF, Warne JP, Foster MT, Pecoraro NC (2007) Glucocorticoids and insulin both modulate caloric intake through actions on the brain, J. Physiol.- London 583, 431-436.

De Lamo, D., Sanborn, A., Carrasco, C., and Scott, D. (1998). Daily activity and behavioral thermoregulation of the guanaco (Lama guanicoe) in winter. Canadian Journal of Zoology 76, 1388- 1393. 
523

524

525

526

527

528

529

530

531

532

533

534

535

536

537

538

539

540

541

542

543

544

545

546

547

548

549

550

551

552

553

554

555

556

557

558

559

560

561

562

563

564

565

566

567

568

569

570

571

572

573

574

575

576

577

Enstrom DA, Ketterson ED \& Nolan Jr V (1997) Testosterone and mate choice in the dark-eyed junco. Anim. Behav.54, 1135-1146.

Faulkes CG, Abbott DH, (1997) The physiology of a reproductive dictatorship: regulation of male and female reproduction by a single breeding female in colonies of naked mole-rats. In: Solomon, N.G., French, J.A. (Eds.), Cooperative Breeding in Mammals. Cambridge Univ. Press, Cambridge, pp. 302-334.

Franklin W (1983) Constranting socioecologies of South America' s wild camelids: the vicuna and guanaco.Pp. 573-629 in J.F.Eisenberg and D.Kleiman, eds.Advances in study of mammalian behavior. Spec. Publ. No. 7, Am.Soc.Mammal, Shippensburg, Pa.

Gottreich A, Zuri I, Barel S, Hammer I, Terkel J (2000) Urinary testosterone levels in the male blind mole rat (Spalax ehrenbergi) affect female preference. Physiol Behav.;69:309-315.

Goymann W, Wingfield JC (2004) Allostatic load, social status and stress hormones: the costs of social status matter, Anim. Behav. 67, 591-602.

Goymann W and Wingfield JC (2004) Allostatic load, social status and stress hormones: the costs of social status matter. AnimalBehaviour 67:591-602.

Jacobs JD and Wingfield JC (2000) Endocrine control of life- cycle stages: a constraint on response to the environment? Condor 102:35-51.

John TM (1965) A histochemical study of adrenal corticoids in pre and post migratory wagtails Motacilla alba and M. flava. Pavo 4, 9-14.

Kenagy GJ and Place NJ (2000) Seasonal changes in plasma glucocorticosteroids of free- living female yellow-pine chipmunks: effects of reproduction and capture and

handling, Gen. Comp. Endocrinol. 117. 189-199.

Ketterson, E.D., and V. Nolan Jr. 1999. Adaptation, exaptation, and constraint: a hormonal perspective. American Naturalist 153:S4-S25.

Knapp R, Moore MC (1997). Male morphs in tree lizards have different testosterone responses to elevated levels of corticosterone. Gen. Comp. Endocrinol. 107, 273-279.

Le PP, Friedman JR, Schug J, Brestelli JE, Parker JB, Bochkis IM \& Kaestner KH (2005). Glucocorticoid receptordependent gene regulatory networks. PLoS Genetics, 1, 159-170.

S. Levine, Stress: an historical perspective, in: T. Steckler, N. Kalin, J.M.H.M. Reul (Eds.), Handbook of Stress and the Brain, Elsevier, Amsterdam, the Netherlands, 2005, pp. 3-23.

Lofts B \& Marshall AJ (1960). The experimental regulation of the sexual cycle in the Brambling Fringilla montifringilla. Ibis 102: 209-214.

Naik DV and George JC (1963) Histochemical demonstration of increased corticoid level in the adrenal of Sturnus roseus (Linnaeus) towards the migratory phase. Pavo 1, 103-105.

Nelson R (2000). An introduction to behavioural endocrinology. Sinauer, Suderland, Mass.

Nespolo RF, Bacigalupe LD \& Bozinovic F (2003) Heritability of energetics in a wild mammal, the leaf eared mouse (Phyllotis darwini). Evolution 57: 1679-1688.

Marino A \& Baldi R (2008) Vigilance patterns of territorial guanacos (Lama guanicoe): the role of reproductive interests and predation risk. Ethology 114, 
578

579

580

581

582

583

584

585

586

587

588

589

590

591

592

593

594

595

596

597

598

599

600

601

602

603

604

605

606

607

608

609

610

611

612

613

614

615

616

617

618

619

620

621

622

623

624

625

626

627

628

629

630

631

632

413-423.

Mattocks PW (1976) The role of gonadal hormones in the regulation of the premigratory fat deposition in the Whitecrowned Sparrow Zonotrichia leucophrys gambelii. Unpublished Master's thesis. Seattle, Washington, Univ. Washing- ton.

Mateo JM, Cavigelli SA (2005) A validation of extraction methods for noninvasive sampling of glucocorticoids in free-living ground squirrels. Physiol Biochem Zool 78:

1069-1084.

McEwen BS, Wingfield JC (2003) What is in a name? Integrating homeostasis, allostasis and stress, Horm. Behav. 57: $105-111$.

Millspaugh JJ, Woods RJ, Hunt KE, Raedeke KJ, Brundige GC, Washburn BE, Wasser SK (2001) Using fecal glucocorticoid assays to study the physiological stress response of elk. Wildlife Society Bulletin 29, 899-907.

Millspaugh JJ, Washburn BE (2004) Use of fecal glucocorticoid metabolite measures in conservation biology research: considerations for application and interpretation. Gen Comp Endocrinol 138:189-199.

Moberg GP (1991) How behavioral stress disrupts the endocrine control of reproduction in domestic animals, Journal Dairy Science. 74, 304-311.

Monclús R, Tiulim J, Blumstein DT (2011) Older mothers follow conservative strategies under predator pressure: the adaptive role of maternal glucocorticoids in yellow-bellied marmots, Horm. Behav. 60, 660-665.

Morton ML \& Mewaldt LR (1962) Some effects of castration on a migratory sparrow (Zonotrichia atricapilla). Physiol. Zool. 35: 237-247.

Mostl E and Palme R (2002) Hormones as indicators of stress, Domest. Anim. Endocrinol. 23, 67-74

Mo“stl E, Rettenbacher S, Palme R (2005) Measurement of corticosterone metabolites in birds' droppings: an analytical approach. Ann NY Acad Sci 1046:17-34.

Muller MN, Wrangham RW (2004) Dominance, aggression and testosterone in wild chimpanzees: a test of the dChallenge hypothesisT. Anim. Behav. 67, 113-123.

Ovejero R and Carmanchahi P (2012) "Stress In Nature? Integrating Physiology, Ecology and Natural History of guanacos (Lama guanicoe)". Proceedings of 2nd Latin-American Mammalian Congress. University of Natural sciences, Buenos Aires.

Ovejero R, 2013. "Variación del nivel de cortisol en función de factores sociales y ambientales en guanacos (Lama guanicoe). Implicancias para la conservación y manejo de las poblaciones silvestres". $315 \mathrm{pp}$, Tesis doctoral. Facultad de Cs. Naturales Univ Nac

Ostner J, Kappeler PM (2002) Seasonal variation and social correlates of androgen excretion in male redfronted lemurs (Eulemur fulvus rufus).

Behav. Ecol. Sociobiol. 52, 485- 495.

Ostner J, Kappeler PM (2002) Seasonal variation and social correlates of androgen excretion in male redfronted lemurs (Eulemur fulvus rufus). Behav. Ecol. Sociobiol. 52, 485- 495.

Pereira RJG, Duarte JMB, Negrão JA (2006) Effects of environmental conditions, human activity, reproduction, antler cycle and grouping on fecal glucocorticoids of free-ranging Pampas deer stags (Ozotoceros bezoarticus bezoarticus), Horm. Behav. 49, 114-122. 
633 Peczely P (1976). E' tude circannuelle de la fonction corticosurrenalienne chez les espe^ces de passereaux migrant et 634 non migrant. Gen. Comp. Endocrinol. 30, 1-11.

635

636

637

638

639

640

641

642

643

644

645

646

647

648

650

651

652

653

654

655

656

657

658

659

660

661

662

663

664

665

666

667

668

669

670

671

672

673

674

675

676

677

678

679

680

681

682

683

684

685

686
Pride RE (2005) High faecal glucocorticoid levels predict mortality in ring-tailed lemurs (Lemur catta), Biological Letters. 1, 60-63.

Puig, S \& Rabinovich, J (1995). Abundancia y distribución de las poblaciones de guanacos. Capít ulo 4. In: Técnicas para el Manejo del Guanaco (Ed. by S. Puig), pp. 57-70. GECS/CSE/UICN, Buenos Aires.

Raedeke K (1979) Population dynamics and socioecology of the guanaco (Lama guanicoe) of Magallanes, Chile. Doctoral Dissertation. College of Forest Resources University of Washington.

Raouf SA, Smith LC, Brown MB, Wingfield JC, Brown CR (2006) Glucocorticoid hormone levels increase with group size and parasite load in cliff swallows. Anim Behav 71:39-48.

Roff, D.A. 1992. The Evolution of Life Histories: Theory and Analysis. Chapman and Hall, New York.

Romero LM, Remage-Healey L (2000) Daily and seasonal variation in response to stress in captive starlings (Sturnus vulgaris): corticosterone. General and Comparative Endocrinology 119, 52-59.

Romero LM (2002) Seasonal changes in plasma glucocorticoid concentrations in free-living vertebrates. General and Comparative Endocrinology, 128, 1-24.

Romero LM (2004) Physiological stress in ecology: lessons from biomedical research. TREE. 19, 249-255.

Romero LM, MJ. Dickens, NE Cyr, The reactive scope model - A new model integrating homeostasis, allostasis, and stress, Horm. Behav. 55 (2009) 375- 389.

Rubenstein DR \& Shen SF (2009) Reproductive conflict and the costs of social status in cooperatively breeding vertebrates. The American Naturalist, 173, 650-662.

Sapolsky RM, Romero LM, Munck MU (2000). How do glucocorticoids influence stress responses? Integrating permissive, suppressive, stimulatory, and preparative actions, Endocr. Rev. 21, 55-89.

Sapolsky RM (2002) Endocrinology of the stress response, in: J.B. Becker, S.M. Breedlove, D. Crews, M.M. McCarthy (Eds.), Behavioral Endocrinology, 2nd ed, Cambridge, Massachusetts, pp. 409-450.

Sheriff MJ, Bosson CO, Krebs CJ, Boonstra R (2009) A noninvasive technique for measuring fecal cortisol metabolites in snowshoe hares (Lepus americanus). J Comp Physiol B 179:305-313

Sheriff MJ, Dantzer B, Delehanty B, Palme R, Boonstra R (2011) Measuring stress in wildlife: techniques for quantifying glucocorticoids, Oecologia 166, 869-887.

Schradin C (2008) Seasonal changes in testosterone and corticosterone levels in four social classes of a desert dwelling sociable rodent, Horm. Behav. 53, 573-579.

Schwabl H,Wingfield JC and Farner DS (1984) Endocrine Correlates of Autumnal Behavior in Sedentary and Migratory Individuals of a Partially Migratory Population of the European Blackbird (Turdus merula). The Auk, Vol. 101, No. 3, pp. 499-507

Sinervo B, Miles DB, Frankino WA, Klukowski M, DeNardo DF (2000) Testosterone, endurance, and Darwinian fitness: natural selection and sexual selection on the physiological bases of alternative male behaviors in sideBlotched lizards. Horm. Behav. 38, 222-233. 
687 Smith JE, Whelan CJ, Taylor SJ, Denight ML, Stake MM (2007) Novel predator-prey interactions: is resistance 688 futile?, Evol Ecol. Res. 9, 433-446.

Smith JE, Monclús R, Wantuck D, Florant GL, Blumstein DT (2012). Fecal glucocorticoid metabolites in wild yellow-bellied marmots: Experimental validation, individual differences and ecological correlates .General and Comparative Endocrinology 178: 417-426.

Soto-Gamboa M, Villalon M, Bozinovic F (2005) Social cues and hormone levels in male Octodon degus (Rodentia): a field test of the challenge hypothesis. Horm Behav

47:311-318.

Soto-Gamboa M, Gonzalez S, Hayes LD, Ebensperger L (2009) Validation of a radioimmunoassay for measuring fecal cortisol metabolites in the hystricomorph rodent Octodon degus. J Exp Zool 311:496-503.

Stearns SC (1992) The evolution of life histories. Oxford: Oxford University Press.

Tarlow EM, Blumstein DT (2007) Evaluating methods to quantify anthropogenic stressors on wild animals, Appl. Anim. Behav. Sci. 102, 429-451.

Tempel DJ, Gutierrez RJ (2004) Factors related to fecal corticosterone levels in California Spotted Owls: implications for assessing chronic stress. Conservation Biology 18, 538-547.

Touma C, Palme R (2005) Measuring fecal glucocorticoid metabolites in mammals and birds: The importance of validation. Ann. NY Acad. Sci. 1046, 54-74.

Vera F, Zenuto RR, Antenucci CD (2012) Differential responses of cortisol and corticosterone to adrenocorticotropic hormone (ACTH) in a subterranean rodent (Ctenomys talarum). Journal of Experimental Zoology A. 317:173-184

Von Holst D (1998) The concept of stress and its relevance for animal behavior, Stress and Behavior 27, 1-131.

Wasser SK, Hunt KE, Brown JL, Cooper K, Crockett CM, Bechert U, Millspaugh JJ, Larson S, Monfort SL (2000) A generalized fecal glucocorticoid assay for use in a diverse array of nondomestic mammalian and avian species. Gen Comp Endocrinol 120:260-275.

Weise CM (1967). Castration and spring migration in the White-crowned Sparrow. Condor 69: 49- 68.

Wingfield JC, Hunt K, Breuner C, Dunlap K, Fowler GS, Freed L, Lepson J (1997) Environmental stress, field endocrinology, and conservation biology. In: Clemmons, JR.; Buchholz, R., editors. Behavioral Approaches to Conservation in the Wild. Cambridge University Press; Cambridge: p. 95-131.

Wingfield JC, Sapolsky RM (2003) Reproduction and resistance to stress: when and how. J Neuroendocrinol 15:711-724.

Wingfield JC (2005) The concept of allostasis: coping with a capricious environment, J. Mammal. 86: 248-254.

Young JK \& Franklin WL (2004) Activity budget patterns in family-group and solitary territorial male guanacos. Revista Chilena de Historia Natural, 77, 617-625.

Young AJ, Carlson AA, Monfort SL, Russell AF, Bennett NC \& Clutton-Brock T (2006) Stress and the suppression of subordinate reproduction in cooperatively breeding meerkats. Proceedings of the National Academy of Sciences of the United States of America, 103, 12005-12010.

739 Zera, A.J. \& Harshman, L.G. (2001) The physiology of life history trade-offs in animals. Annual Review of Ecology

740 and Systematics, 32, 95-126. 
741

742

743

744

745

746

747

748

749

750

751

752

753

754

755

756

757

758

759

760

761

762

763

764

765

766

767

768

769

770

771

772

773 


\section{Figure 1 (on next page)}

HPA \& HPG axis activity patterns throughout the study period

HPA \& HPG axis activity patterns throughout the study period. Blue line= the seasonal baseline fecal testosterone profile (defined by $y=0.0041 \times 5-0.1102 \times 4+1.0889 \times 3$ $\left.4.6819 \times 2+7.914 x-0.7892 ; r^{2}=0.7231\right)$, Pink line $=$ the seasonal baseline fecal cortisol profile (defined by $y=0.0743 \times 5-1.9677 \times 4+19.136 \times 3-82.442 \times 2+147.4 x-58.902 ; r^{2}=$ 0.806). There was marked adrenal and gonadal activity during the breeding and nonbreeding $(\mathrm{Cl}=7.661734-12.057391$, mean $=25.75864 / 15.89907$ respectively $)$ season respectively for the male groups, the GCs and T response was due to seasonal variation in the guanacos highlighting the individual's energetic demands according to life-history strategies. 


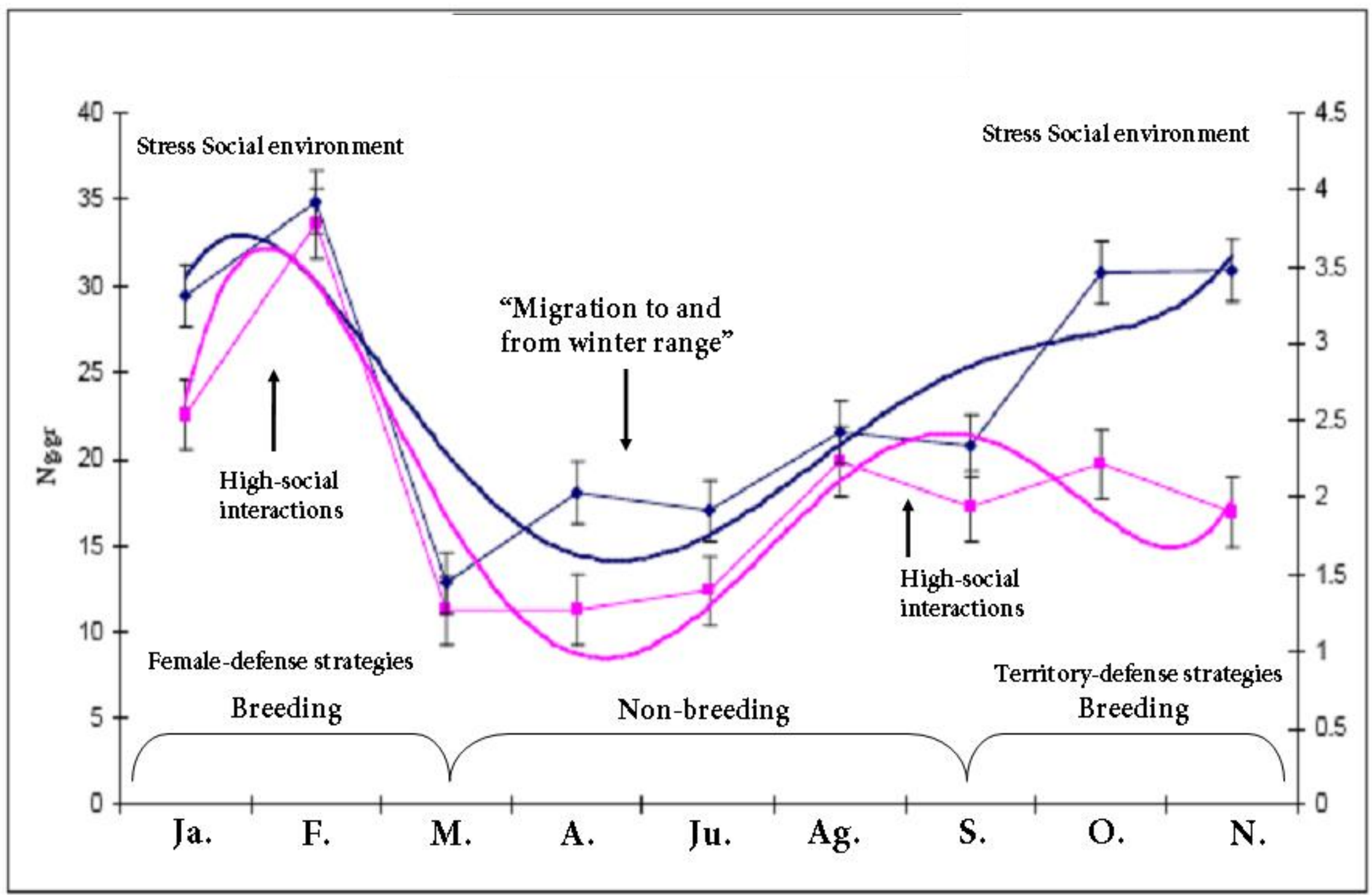




\section{Figure 2 (on next page)}

The reactive scope model for guanacos

Most studies measure only one physiological mediator at a time, here the concentration of two mediators (cortisol-C/testosterone.T) is placed on the $\mathrm{y}$-axis at a given time point. The mediators are correlated in terms of the functional role that each one plays in the normal reactive scope range. In other words, both mediators encompass responses for coping with predictable and unpredictable changes in the environment. The values of each mediator are presumed to exist in four general ranges. The minimun (5-10 Ng.gr for C;1-2 Ng.gr for T) and maximun (20-35 Ng.gr for C;3-4 Ng.gr for T) concentration of the mediator was presumed to constitute a threshold. The results show the ranges (double arrows) of predictive/reactive homeostasis (PH/RH) and homeostatic overload/failure, the stress-gonadal and feedback response (gray circles) indicates the max-min activity patterns for HPA \& HPG axis during one year. The $\mathrm{C}$ activity patterns in guanacos shows two peak of $\mathrm{RH}$ (dotted lines) in the reproductive season, between Ag./O. males adopts a territory-defense strategies at the beginning of the reprod. season; during Ja./F. males changes to a female-defense strategies at the ends of the reprod. season. These results consist of the seasonal set of point ranges for the physiological mediators. 


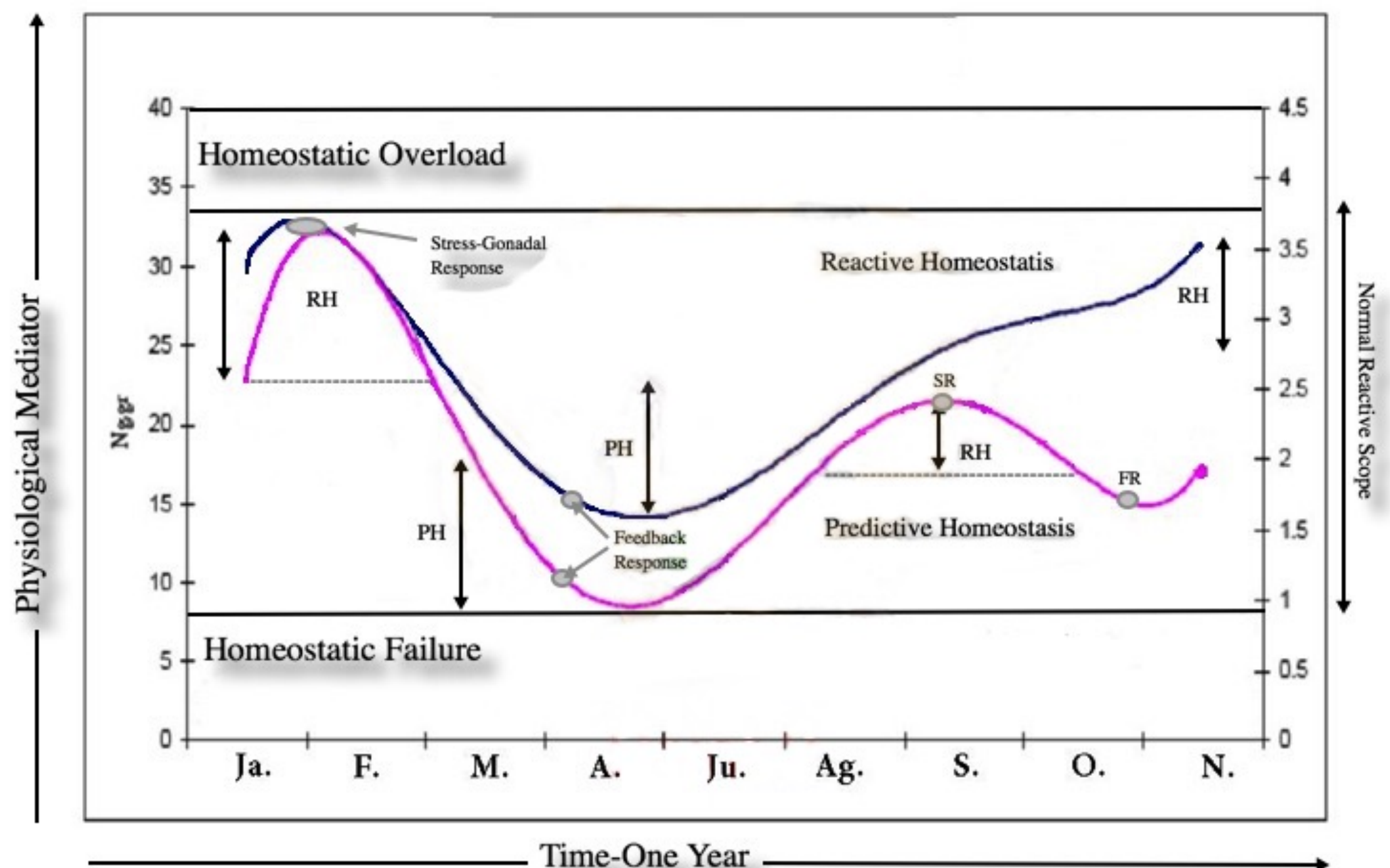

